\title{
El libro de McFadden «Christianity confronts communism» 1
}

Charles McFadden, autor de esta obra, ha dedicado su actividad intelectual, como escritor, a una investigación profunda de la ideología comunista. Han pasado ya unos cuantos años desde que publicó su estupendo análisis del comunismo en su obra The Philosophy of the communism. Desde entonces McFadden ha seguido pensando, y con razón, que la ideología marxista sigue en pie, con toda la fuerza que representa el hecho de que hoy en día sigue siendo la guía ideológica a la que está sometida una buena parte de la humanidad. Esto es lo que le ha hecho volver sobre el tema.

En este segundo libro sobre la ideología marxista el autor ha procedido con el mismo rigor filosófico e histórica, habida cuenta de que el comunismo marxista se ha presentado siempre como una filosofía de la total realidad con su materialismo dialéctico y como una aplicación lógica en el desarrollo de los hechos históricos con su materialismo hiștórico.

La obra está dividida en nueve capítulos o secciones, en cada una de las cuales se ofrecen cuestiones acerca de temas fundamentales en relación con el marxismo, se exponen las afirmaciones marxistas, se interpela a los lectores sobre interrogantes que surgen de las tesis marxistas. La peculiaridad que ofrece este libro, de poder servir para cursos sobre marxismo en teología y ciencias sociales y así poder posibilitar y provocar la discusión sobre temas de

1. McFadden, Ch., Christianity confronts Communism. Franciscan Herald Press, 1434 W. 51st St., Chicago, III. 60609; 423 p. 
flagrante actualidad, el autor se la debe, al menos en parte, al hecho de que, mientras en Rusia, en lo correspondiente a la High School y en la universidad, un alto porcentaje de estudiantes estudian el inglés teniendo además numerosos cursos académicos en los que se les adoctrina acerca de la fuerza y de la debilidad de la sociedad capitalista, en América, y nosotros añadiríamos también en Europa, por el contrario, no es corriente el que los estudiantes estudien el ruso o se preocupen en profundidad de la filosofía del marxismo o de la estructura soviética. Sería el caso de dos equipos enemigos entre los cuales hay un conocimiento perfecto del uno por parte del otro, al paso que el primero desconoce casi completamente al segundo, con todo lo que este conocimiento por una parte, o la ignorancia por la otra, pueden llevar consigo en el conflicto continuo entre ambos equipos.

Dado que el tema es de suma actualidad, vamos a ofrecer a nuestros lectores una reseña lo más amplia posible, dentro de los límites de que podemos disponer en estas páginas. Presentamos los distintos temas según son expuestos en el libro.

Tenemos en primer lugar una especie de introducción atendiendo a los presupuestos históricos que dan origen al fenómeno de la aparición del comunismo en el mundo. La intención de esta primera parte es capacitar al lector para entender la naturaleza de las fuerzas sociales existentes en los siglos XIII$\mathrm{XVIII}$ con su posibilidad de influencia en el nacimiento del marxismo. Evidentemente hay que reconocer las razones que han favorecido el planteamiento de los problemas que dan origen a la reacción comunista. Elementos tales como la falta de formación intelectual y la pobreza de las masas posibilitaron la argumentación marxista y, al mismo tiempo, impidieron que esas masas ignorantes fuesen capaces de detectar posibles soluciones equivocadas ofrecidas por el marxismo. Asimismo, quien nada tenía que perder en una aventura que ofrecía esperanzas de redención, aceptaría todo lo que representase una promesa de salvación. Las soluciones mismas que conllevan un bienestar material pueden favorecer lo mismo el empleo que el paro, y pueden llegar hasta a crear un consumismo que lleve a una crisis de la sociedad. Fueron muy tentadoras las motivaciones comunistas con su crítica de la riqueza y de la religión aliada con el capitalismo, presentándose así con un tinte de mesianismo salvador. El liberalismo intelectual, el liberalismo religioso y moral y el liberalismo político y económico ofrecieron una serie de interrogantes, muy legítimos a veces, que fundamentaron una crítica marxista polifacética, enfrentada con estructuras capitalistas de la sociedad y con elementos religiosos que parecían frenar este entusiasmo redentor. 
El problema, por parte del marxismo, se planteó en lo acuciante de la economía (Marx), y se quiso justificar con una ideología (Engels). Así, pues, una teoría y una práctica serán las características del marxismo. En este aspecto, las nuevas generaciones de hoy, al oír lo que las generaciones que les han precedido cuentan del marxismo, ante la adaptación del mismo a nuevos tiempos y a países distintos, caen en el error de que el marxismo ha cambiado en sus principios básicos, en una palabra, en su ideología. A este propósito, McFadden, muy respetuoso con la jerarquía eclesiástica, llama, sin embargo, la atención sobre una Pastoral Letter on Marxist Communism de noviembre de 1980 en la que se decía a los fieles que el marxismo es más bien un sistema de acción que una teoría coherente, esencial sí, pero subordinada a la primera. El texto enjuiciado por McFadden es éste:

«Evidentemente, el marxismo es menos una teoría lógicamente coherente que un sistema de acción del que la teoría forma una parte esencial pero subordinada. La actividad política y revolucionaria de la clase trabajadora en vistas a una emancipación política, define a la vez el valor práctico y la verdad teórica. Los principios teóricos del movimiento se basan en la praxis histórica. Es decir, más bien que una filosofía, el marxismo es, en sí mismo, un movimiento social que surge, inevitable aunque libremente, de condiciones económicas del capitalismo industrial que, en su desarrollo, crea las estructuras necesarias que legitiman y sostienen su actividad práctica. Éste fue, al menos, el concepto que tuvo Marx de la lucha social».

De todos modos, McFadden piensa que estas palabras admiten que el marxismo es una teoría lógica y extremadamente coherente. $Y$ si este texto quiere decir que, según el marxismo, los principios del materialismo histórico se derivan del estudio de la historia del hombre a partir de los tiempos primitivos, ninguna mejor base que ésta podría encontrarse para una filosofía de la historia. Pero si este texto, según parece, quiere decir que los principios marxistas del materialismo histórico son dependientes de la actividad revolucionaria comunista, ésta sería una afirmación falsa a todas luces, ya que dichos principios fueron desarrollados por Marx y Engels algunas décadas antes de la revolución comunista del año 1917. Aun Lenín, que dirige la revolución, escribió antes de hacerla. Es decir, la teoría no nace de la acción revolucionaria sino ésta de aquélla, tanto en Rusia como en los países donde se ha llevado a efecto. Otra cosa es lo que ha podido ser la ocasión de la elaboración de la teoría. En una palabra, parece que más bien hay que decir que el materialismo históricos es una aplicación del materialismo dialéctico. Tampoco agrada a McFadden la frase de que la dictadura del proletariado surge «inevitablemente» aunque «libremente» de las condiciones económicas del capitalismo industrial, sino según un determinismo necesario atendida la mentalidad comu- 
nista. Por nuestra parte, recordaríamos aquí al padre de la criatura, la dialéctica hegeliana con su proceso natural de tesis, antítesis y síntesis.

De hecho, ¿cuáles son los principios de la ideología marxista según el anamis que el marxismo hace del universo? Tres, según él, son las leyes que dan idzón de la existencia del movimiento: ley de tensión de los opuestos, ley de la negación y ley de la transformación y evolución. La primera origina el movimiento, la segunda, por negación de contrarios, llega hasta la vida; la tercera explica la transformación de los seres.

El autor somete a crítica estas leyes recordando, por ejemplo, que no es lo mismo oposición que contrariedad; $y$, si bien es verdad que si el grano de trigo no muere no nacerá la espiga, a nadie se le ocurre decir que la espiga no sea la continuación de la vida existente en el grano. Como siempre, también aquí el marxismo dice verdades a medias que se hacen pasar por toda la verdad no respondiendo así a la autenticidad.

Por nuestra parte añadiriarnos, sin embargo, que, dado que la posición del que filosofa sirviéndose única y exclusivamente de la razón, se encuentra en un callejón sin salida cuando se enfrenta con el problema del ser (Heidegger, por ej., se muere añorando a ese ser que no acaba de desvelársele con una auténtica transcendencia), no nos extraña que se presenten soluciones, como la marxista, que lleven en su raíz una contradicción metafísica, como lo es también el evolucionismo absoluto partiendo de una realidad imperfectísima, llámase ésta idea, materia, etc. A todos los filósofos ateos habría que recordarles que, ante un callejón que tiene una salida como la que ellos presentan con una contradicción metafísica en la raíz, lo prudente sería callarse tales soluciones y situarse en la humilde espera de quien reconoce las dificultades insuperables que tiene la pura razón para encontrarse coñ un Dios personal. ¿Por qué no se piensa que pueda haber quizás otro medio que desvele al hombre el ser con una luz diferente que, como a Marcel, le ofrezca un camino que, no por ser el de la fe, impone un dogma a la razón sino que, en el terreno de lo racional, le ofrezca una ayuda para su aceptación? Tomás nos da unas pruebas racionales de la existencia de Dios que no serán capaces, vamos a concederlo, de desvelar por fuerza de la pura razón lo misterioso de la trascendencia-inmanencia del ser, pero que, con el apoyo de la revelación (¿acaso ésta es imposible?) evitarían el callejón sin salida y la solución negativa de los filósofos ateos. Creo que en esta línea se mueve McFadden en la reflexión crítica que hace al aceptar las pruebas filosóficas de la existencia de Dios según los diferentes valores metafísicos, físicos y morales. 
III

Descendiendo ya al hombre concreto hay un problema que en el marxismo queda muy comprometido: es el problema del ser mismo del hombre. McFadden critica la postura marxista atendiendo a la racionalidad del ser huma-" no. ¿Qué piensa el comunismo marxista de la espiritualidad humana? ¿Qué sentido tienen en el marxismo los conceptos de materialidad y espiritualidad? ¿Se da cuenta hoy la juventud intelectual marxista de la transcendencia que implica la solución objetiva de estos problemas? ¿Qué categoría específica filosófica se les da al hombre y al animal? $\mathrm{Y}$, por el contrario, pensando como piensa el marxista, ¿habría que extrañarse de que en una concepción materialista del hombre se llegue a la justificación del aborto en determinadas circunstancias de la evolución del ser humano? También al marxismo, como a todo materialismo, se le presenta el difícil problema de la libertad humana desde el momento en que la evolución, con sus leyes, le lleva a establecer una relación necesaria entre conocimiento y aplicación del mismo a la praxis, lo que va a chocar evidentemente con la libertad de acción necesaria para poder hablar, si se es lógico, de un auténtico domiṇio del hombre sobre la materia y sobre la naturaleza. El criterio de verdad en el marxismo será la praxis; consecuentemente, la verdad no sobrepasará el ámbito de lo material; muy de acuerdo todo esto con la negación de la realidad espiritual del hombre.

IV

Es cierto que el marxista no es un fatalista del horóscopo o de los de los signo del zodíaco, de los de las cartas, o de los de las bolas de cristal, pero sí afirma que las fuerzas económicas determinan el organismo social. Así el comunismo sería la conclusión necesaria de una negación del capitalismo. Pero entonces, ¿por qué esforzarse por un desarrollo intelectual que dirija el adiestramiento de las nuevas estructuras? Siendo la mente humana simplemente $y$ siempre un reflejo de las condiciones sociales existentes, no se comprende que sugiera, dirija e intente dominar esas condiciones de las que es un resultado, es decir, no se comprende que se exprese con la violencia por precederlas y crearlas. Con esta afirmación, precisamente, el marxismo está insinuando, al mismo tiempo que la niega, la primacía de lo espiritual sobre lo material. Solamente a base de esta primacía se le puede conceder a Marx el haber podido rechazar, como afirma el marxismo, el materialismo del siglo XVIII. El progreso, resultado de las ideas y de sus conexiones mediante los juicios y raciocinios, jamás han sido la característica de los animales, los cuales, sin embargo, pueden realizar a veces estúpidamente, obras tan perfectas como las del hombre. Pero el marxista, con su afirmación de la materia puesta al principio del 
ser, de hecho ha renunciado al principio metafísico de que nada sucede $\sin$ una razón suficiente al implicar el materialismo en su raíz que los efectos pueden superar la capacidad potencial de sus causas. Todavía si nos hubieran dicho que la realidad original es espíritu - como hicieron los hegelianos- podría haber una apariencia de verdad en tal capacidad potencial radical. Pero es inútil discutir; cuando se ha renunciado a la metafísica (Heidegger dirá un día: cuando se ha «perdido el ser», se puede permitir uno tranquilamente el lujo de la contradicción en la raíz del sistema. Y no cabe duda que el modo de producción económica influye en la estructura de la sociedad, pero aquí, de nuevo, no hay que confundir lo que es causa ocasional con lo que es la verdadera causa que hace la estructura. Se habla también del factor económico como el determinante de las guerras, lo cual puede no dejar de ser cierto a veces; pero, ¿no tenemos hoy en día revoluciones por razón de opresiones, dictaduras, lesión de derechos humanos, etc., etc.? Y para los que quieran ver ¿acaso las naciones sometidas al comunismo no ofrecen una especie de bancarrota, filosófica, social y económicamente consideradas?

\section{V}

Al analizar el pensamiento marxista acerca de la propiedad privada, McFadden llama la atención de lo que se piensa por muchos en el marxismo sobre este problema. Nos recuerda que el marxismo no se opone a una sociedad basada en la propiedad privada porque en ella no reciba el trabajador la justa recompensa de su trabajo; esto, a' lo más, sería un segundo aspecto de la objeción marxista. Es más, el marxismo afirma que el fruto del trabajo pertenece al trabajador y éste no debe ser despojado de él. La cuestión principal, que es la objeción fundamental en el marxismo, contra lo que se denomina propiedad privada en la sociedad capitalista, es el modo de concebir la relación individuo-colectividad. En el marxismo, la colectividad no es una entidad distinta del individuo, ni el individuo es parte de la colectividad, sino que cada hombre, y juntos todos los "cada uno», constituyen la colectividad. McFadden establece un paralelo entre la concepción marxista «individuo-comunidad» con la concepción de esa relación en una Orden religiosa. En ésta el individuo trabaja para la Orden, pero todo lo de la Orden le pertenece; en suma, como debe ser entre auténticos hermanos en Cristo. Pero esto es lo que no sucede en la sociedad basada en la propiedad privada tal como se da en la sociedad capitalista. Es aquí donde se da la alienación del trabajador de la que el marxismo pretende liberarle. $Y$ así entendemos ahora cómo el marxismo no se avergüence de hablar de dictadura del proletariado que no es, como en la sociedad capitalista, una dictadura instrumento de fuerza en manos de una minoría explotadora... Otra vez tenemos aquí una verdad ideal que sería estu- 
penda si los marxistas fueran unos hermanos en Cristo (en el que no creen, por su ateísmo) y si los hechos no contradijesen a las teorías. Ahí están los hechos de los gobiernos marxistas sin excepción: Polonia, Hungría, Checoslovaquia, Vietnam del Sur, Cuba y últimamente Afganistán con la negación radical de las libertades políticas, tan exigidas por los comunistas en los países en que no se encuentran gobernando en solitario... Si no existiesen estos hechos contrarios, valdría la pena equiparar comunismo y cristianismo.

VI

El texto señala como una de las mayores tragedias en los países comunistas la pérdida de la fe cristiana en la juventud. Educados como están en una sociedad atea. McFadden experimentó personalmente la total indiferencia de los jóvenes a este respecto. Para las juventudes de los países dominados por el comunismo, la religión es algo que ha sido superado por la ciencia moderna; se trata de una superstición profesada por la gente sencilla e ignorante.

Y ¿qué pensar de una posible ética comunista? En el caso de países como el Japón, vacíos de un concepto sobre la Divinidad, se da una moralidad en relación con una cierta norma de la misma, como, por ejemplo, el buen nombre de la familia, de la sociedad, de la empresa en que se trabaja, el honor de su patria, etc. En el marxismo comunista la calificación de una acción viene dada por su relación con la lucha de clases del proletariado, pero teniendo en cuenta que ha de atenderse a esta relación como a una verdad siempre relativa debido a la evolución de la sociedad, de modo que la misma acción, que en una situación es buena para esa lucha de clases del proletariado, puede ser perjudicial en otra situación. De ahí que esa ética pueda tener caras y aspectos tan diversos y engañar tan fácilmente a los incautos.

Meta del marxismo es la utópica realización de una sociedad ausente de todo egoísmo $\mathrm{y}$, por cierto, prescindiendo de todo premio eterno en un más allá. En el cristianismo diríamos que, algunos al menos (los santos), han conseguido esta meta ayudados por la perspectiva de una futura felicidad y posesión de Dios por las que valía la pena luchar contra el propio egoísmo con sacrificio. ¿Cuál será el secreto del marxismo ateo para alcanzar esa meta en toda la humanidad?

$$
\text { VII }
$$

¿Cuál es el carácter peculiar de la revolución proletaria marxista? El marxismo piensa que la explicación capitalista tiene un límite, alcanzado el cual, las masas se alzan en una acción revolucionaria contra el Estado que protege a la estructura opresora. Pero la verdad es que en Estados Unidos, por ejemplo, 
no ha sido la explotación del capital lo que ha llevado a estos desastres, sino las exigencias exageradas y satisfechas por parte de la patronal = un mayor bienestar de los trabajadores = lo que ha inducido a éstos a frenar sus exigencias para no llegar al desastre (ejemplos la Chrysler y la Ford, al tiempo en que escribe el autor). Es decir, tendríamos aquí que la explotación ha sido al revés, y ha sido esta explotación al revés lo que ha llevado a una sociedad imposible. El autor continúa sometiendo a análisis crítico, con hechos que revelan lo contrario, la tesis marxista de la concentración de la propiedad en pocas manos, la de su revolución proletaria como voluntad de las masas, la del partido único como instrumento de la revolución por la libertad. En realidad, Polonia, Afganistán, el telón de acero y la supresión de todos los demás partidos donde existe la así llamada dictadura del proletariado, son ejemplos contrarios. ¿Se pueden comparar los progresos de los países comunistas sometidos a la evolución del proletariado con los progresos de una Alemania y de un Japón libres? La violencia ha sido siempre el medio característico de esa revolución que, en vez de resultar en auténticas democracias dê libertad cuando de países oprimidos se trataba, ha sido más bien el instrumento adecuado para que el partido comunista terminara con todos los demás partidos en libertad. ¿Quién podría citarnos un solo país dominado por el régimen comunista donde haya partidos políticos? Minorías intelectuales o étnicas están no sólo oprimidas sino hasta sin posibilidad de encontrar su libertad fuera de la Rusia que se dice democrática por excelencia.

VIII

En este apartado intenta el autor: a) proporcionar a los lectores un bosquejo de los antecedentes históricos y de las circurıstancias que acompañan a la supremacía soviética en la mayor parte, por no decir en todos, de los países controlados por la ideología comunista; b) presentar un análisis del estado actual de la Iglesia en estos países; c) efectuar una evaluación-perspectiva en relación con lo que pudiera ser un mejoramiento de las relaciones futuras entre la Iglesia y el Estado en los países comunistas; d) recomendar fuentes en las que los lectores interesados pueden encontrar material adecuado de investigación acerca de todos estos problemas. Aquí encontrarán también los sociólogos aliciente para sus estudios sobre el fenómeno religioso en su relación con lo político.

IX

Finalmente, la última parte informa a los lectores acerca de los problemas con los que el cristiano tiene que verse cuando ha de entrar en diálogo con intelectuales o simples ciudadanos que viven en los países marxistas. A este 
respecto no son fáciles los puntos de contacto que se han verificado atendiendo al comportamiento, por un lado, de lo que se ha llamado el eurocomunismo o la ostpolitik por otro. Asimismo, la teología de la liberación ha tenido un enfoque especial en las naciones donde las dictaduras de derechas han proporcionado un estupendo caldo de cultivo para posturas filocomunistas o para posibles dictaduras de izquierdas. Entonces, ¿qué hacer, cómo comportarse, cómo cooperar en puntos en los que, como en la defensa de los derechos humanos, parece que hay convergencia entre el marxismo y el cristianismo? En estos casos la tentación de una actividad política por parte de los cristianos en cuanto tales ha sido muy grande por parte de los miembros de la Iglesia a pesar de las reservas manifestadas por la Cabeza visible de la cristiandad católica. ¿ ¿ómo dialogar con el comunismo? En una palabra, terminaríamos diciendo que la obra que presentamos es de suma actualidad e importancia para quien, sintiendo en cristiano, se preocupa por el posible diálogo con una ideología con la que de hecho está enfrentado, que ecª́ ahí, en ese mundo en que nos ha tocado vivir.

F. CASADO 